\title{
The impact of internet-based cognitive behavior therapy on work ability in patients with depression - a randomized controlled study
}

This article was published in the following Dove Press journal:

International Journal of General Medicine

19 May 2017

Number of times this article has been viewed

\author{
Dominique Hange' \\ Nashmil Ariai' \\ Marie Kivi \\ Maria CM Eriksson' \\ Shabnam Nejati' \\ Eva-Lisa Petersson ${ }^{1,3}$ \\ 'Department of Public Health \\ and Community Medicine/ \\ Primary Health Care, Sahlgrenska \\ Academy, University of Gothenburg, \\ Gothenburg, Sweden; ${ }^{2}$ Department of \\ Psychology, University of Gothenburg, \\ Gothenburg, Sweden; ${ }^{3}$ Narhalsan \\ Research and Development Primary \\ Health Care, Region Vastra Gotaland, \\ Gothenburg, Sweden
}

Objectives: The aim of this randomized controlled trial (RCT) was to investigate the effects of internet-based cognitive behavior therapy (ICBT) treatment for depression compared to treatment-as-usual (TAU) on improving work ability and quality of life in patients with mildto-moderate depression. We also examined whether patients treated with ICBT returned to work more rapidly, that is, had fewer days of sick leave, than patients treated with TAU.

Design: This study is based on material from the PRIM-NET RCT that took place between 2010 and 2013.

Setting: Primary care centers in Region Vastra Gotaland, Sweden, population about 1.6 million. Patients: A total of 77 patients with depression randomized to either ICBT (46 patients) or TAU (31 patients). Mean age of participants was 35.8 years, and $67.5 \%$ were women.

Main outcome measures: Work ability was measured with the Work Ability Index, depressive symptoms with Montgomery Asberg Depression Rating Scale - self-rating version (MADRS-S), quality of life with EuroQoL-5D (EQ-5D), and number of sick leave days.

Results: Both groups showed an association between improved work ability and reduction of depressive symptoms and between improved work ability and better quality of life. ICBT could not be shown to improve work ability more than TAU among patients with mild-to-moderate depression. There were no differences between the groups concerning number of patients with sick leave or number of sick leave days.

Conclusion: Our study indicates that a high level of work ability has an association with high health-related quality of life in patients with mild-to-moderate depression, whether they are treated with ICBT or TAU. ICBT has previously been found to be cost-effective and can be seen as a good alternative to TAU. In addition to the ICBT, an intervention oriented toward the work place might improve work ability and reduce the number of sick leave days among patients with depression.

Keywords: depression, EQ-5D, ICBT, primary care, sick leave, WAI

\section{Introduction}

Depression is known to be associated with disability and loss of quality of life. ${ }^{1,2}$ In the treatment of patients with depression, it is important to focus not only on the curative process but also on support for daily life activities. During the past 10 years, cognitive behavior therapy (CBT) has become more common and useable as treatment for patients with depression, a common group in primary care settings. ${ }^{3}$ One form of CBT is internet-based CBT (ICBT) where the patient has access to the program outside the clinic and receives support each week from a therapist by email or telephone. Studies show that work ability does not increase to the same extent and at the same pace as the depression lapse..$^{4-6}$ Depression is more related to poor work performance than
Correspondence: Dominique Hange Department of Public Health and Community Medicine/Primary Health Care, University of Gothenburg, PO Box 454, SE 405 30, Gothenburg, Sweden

Tel +46 3I 7736849

Fax +46317781704

Email dominique.hange@vgregion.se 
physical conditions. ${ }^{7}$ Improved outcome in terms of depression or anxiety reduction after CBT treatment may not be directly associated with earlier return to work. Work ability is determined by many more factors than solely the patient's own mental state. Returning to work (RTW) is dependent not only on the individual's work ability and cognitive function but also on environmental, social, and economic factors. ${ }^{8}$

Patients with depression account for a large portion of health care consumption, incurring considerable costs for the individual patient and for society as a whole because of reduced work ability and delayed ability to return to work. ${ }^{9}$ The largest economic detriment that is associated with depression seems, however, to be the loss of productivity occurring after the individuals have returned to work. ${ }^{6,10}$

Randomized controlled trials (RCTs) of CBT as a treatment for patients with mild-to-moderate depression have shown the same or better effect than other forms of therapy, including drug therapy. ${ }^{11}$

The aim of this RCT was to investigate the effects of an ICBT compared to treatment-as-usual (TAU), with regard to improving work ability and quality of life in patients with mild-to-moderate depression. We also wanted to examine whether patients treated with ICBT returned to work more rapidly, that is had fewer days of sick leave, than patients treated with TAU.

\section{Patients and methods}

From March 2010 to March 2013, an RCT of treatment of mild-to-moderate depression in primary care, comparing ICBT and TAU, that is the PRIM-NET study, took place in Region Vastra Gotaland, Sweden. ${ }^{12}$ All patients with mildto-moderate depression 18 years or older at 16 different primary care centers (PCCs) were invited to participate. A psychologist/psychotherapist conducted an assessment for $\sim 1$ hour, which included a diagnostic interview. After the interview, questionnaires were administered to the patients by a registered nurse. Inclusion criteria were as follows: diagnosed with depression according to the Mini International Neuropsychiatric Interview (M.I.N.I. version 6.0.0b) and a Montgomery-Asberg Depression Rating Scale - self-rating version (MADRS-S) score $<35 .{ }^{13,14}$ Exclusion criteria were as follows: found to be at a risk of suicide or were diagnosed with substance/alcohol dependency or any severe psychiatric disorder or unemployment, retirement, or other reasons for not working.

All patients received written and oral information about the study. Questionnaires included background factors, education, occupation, marital status, physical activity during leisure time, current antidepressant use (sertraline, citalopram, escitalopram, clomipramine, fluoxetine, mirtazapine, and/or venlafaxine), amount of sick leave during last year, and current sick leave. More about the recruiting procedure could be found Kivi et al and Hange et al. ${ }^{12,15}$

Included patients were randomized to either ICBT or TAU by an independent research unit at the University of Gothenburg. The randomization procedure occurred consecutively for all patients across PCCs. This made it impossible, at a specific PCC, to predict the allocation of patients. In addition to usual care one group received ICBT (group A, TAU+ICBT, group B, TAU). Of the 77 patients included in this study, there were 46 in the ICBT group and 31 in the TAU group (Figure 1).

\section{Treatment conditions in ICBT and TAU}

The ICBT treatment material used was a commercially available program in Swedish called Depressionshjalpen ${ }^{\circledR}$. The program is based on CBT techniques, more specifically Behavioral Activation ${ }^{16}$ with components from Acceptance and Commitment Therapy. The treatment period was defined as 12 weeks. The material consists of internet access to seven modules, each encompassing 8-10 slides of short texts, narrated explanatory models, and/or videos. Within the 12 -week treatment period, 20 individuals $(56 \%)$ of the ICBT participants completed seven modules. The average number of completed modules was 5.1 (range 0-7, SD 1/4 2.6, median $1 / 47$ ). The login time ranged from 0 to 868 minutes with a mean time of 249 minutes (median 188 minutes).

Patients who were randomized to TAU group received TAU at the participating PCC. The treatments offered to TAU patients were not influenced in any way by the PRIMNET project except that they were not allowed participation in any internet-based treatment during the study period. Therefore, TAU could include a diverse mix of antidepressants, scheduled contacts with personnel at the PCC such as general practitioners or nurses, referral to regular psychotherapy (often preceded by a nonnegligible waiting period), or combinations of these options depending on routines and available resources at each PCC. ${ }^{12}$

\section{Outcome measures}

The following self-assessment instruments were used: Work Ability Index (WAI), MADRS-S, and EuroQoL-5D (EQ-5D). All outcome measures were collected at baseline and at 3, 6, and 12 months. WAI was used to measure work ability and is a summary of seven dimensions and 10 items of work. ${ }^{17}$ As some items are not sensitive to change over time, ${ }^{18}$ we used 


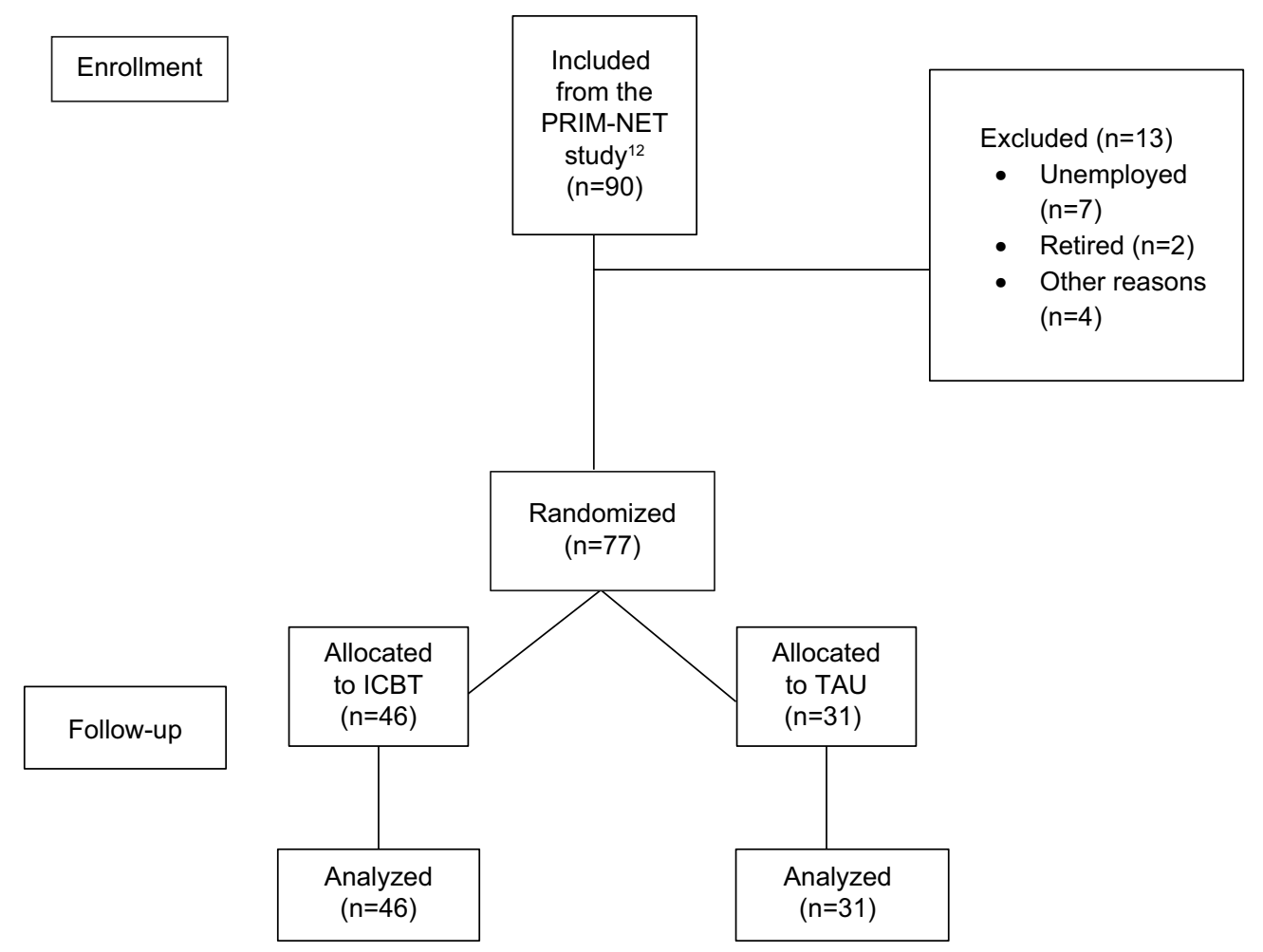

Figure I Flowchart over the inclusion, where 13 persons were excluded from the study; seven were unemployed, two were retired, and four had other reasons for not working.

Abbreviations: ICBT, internet-based cognitive behavior therapy; TAU, treatment-as-usual.

one single question "Current work ability compared with the lifetime best," with possible scores of 0 ("completely unable to work") to 10 ("ability at its best"). The validity of the single question on work ability has been demonstrated. ${ }^{19}$

MADRS-S is a commonly used scale to follow the lapse of patient's depressive symptoms. The scale is designed to be sensitive to change. ${ }^{20}$ MADRS-S evaluates depression based on nine items, and each item yields a score of 0 (absent) to 6 (extreme): apparent sadness, reported sadness, inner tension, reduced sleep, reduced appetite, concentration difficulties, lassitude, inability to feel, pessimistic thoughts, and suicidal thoughts. The scores for all nine items were added, and cutoff scores for the MADRS-S were defined for level of depression (depression: 0-12=minimal, 13-19=mild, $20-34=$ moderate, $\geq 35=$ severe). MADRS-S is well suited for use in primary care. ${ }^{21}$

To measure health-related quality of life (HRQOL), we used EQ-5D. ${ }^{22}$ The UK EQ-5D index tariff, based on a representative sample of the UK general public, was used. The index provides a single value for all the hypothetical health states described by the EQ-5D. ${ }^{23,24}$

Sick leave was measured as self-reported days (whether full- or part-time) out of work with sickness benefits.

\section{Statistical methods}

The background data were analyzed using descriptive statistical methods, and frequencies were compared by using Chi-square test. Baseline between-group differences in demographic data and pretreatment measures were analyzed with independent $t$-tests and nonparametric tests.

Within-group changes in questionnaires were analyzed using paired-samples $t$-tests. Mean values of intraindividual change from baseline to 3, 6, and 12 months' follow-up were compared between ICBT treatment group and TAU group using student's $t$-test or the Mann-Whitney $U$-test. Linear regression analysis was used in order to compare changes between the groups over time. We report the average values for each variable in Tables $1-3$. WAI is independent variable in both Tables 2 and 3. In Table 3, delta-WAI (the meaning of delta in this particular study is the difference or change in, for example, WAI from baseline to 3 months) is the independent variable. $p$-values $<0.05$ were considered to be significant.

\section{Power calculation}

Based on the power calculation, the design of the study required 71 patients in each group for the possibility to detect a difference of more than $10 \%$ improvement in the ICBT group 
Table I Adjusted mean values of work ability, MADRS-S, EQ-5D, and sick leave at baseline, 3, 6, and 12 months

\begin{tabular}{|c|c|c|}
\hline Variables & ICBT mean (SD) & TAU mean (SD \\
\hline \multicolumn{3}{|l|}{ WAI } \\
\hline Baseline & $5.512(2.354)$ & 6.241 (2.402) \\
\hline 3 months & $6.633(2.185)$ & $7.478(2.422)$ \\
\hline 6 months & $7.387(2.110)$ & $8.200(1.715)$ \\
\hline 12 months & $7.437(2.376)$ & $7.500(2.484)$ \\
\hline \multicolumn{3}{|l|}{ MADRS-S } \\
\hline Baseline & I8.884 (6.348) & $21.226(6.325)$ \\
\hline 3 months & $12.133(8.030)$ & $10.26 \mid(8.623)$ \\
\hline 6 months & $9.500(6.627)$ & I0.39| (8.249) \\
\hline 12 months & $10.250(8.825)$ & $10.583(7.4 \mid 2)$ \\
\hline \multicolumn{3}{|l|}{ EQ-5D } \\
\hline Baseline & $0.661(0.210)$ & $0.585(0.223)$ \\
\hline 3 months & $0.754(0.208)$ & $0.767(0.187)$ \\
\hline 6 months & $0.813(0.189)$ & $0.817(0.165)$ \\
\hline 12 months & $0.817(0.204)$ & $0.802(0.162)$ \\
\hline \multicolumn{3}{|l|}{ Sick leave } \\
\hline Baseline to 3 months & $52.846(33.175)$ & $67.400(31.64 I)$ \\
\hline 3 to 6 months & 71.778 (28.27I) & $73.750(45.45 \mathrm{I})$ \\
\hline 6 to 12 months & 87.857 (108.82) & $53.600(48.112)$ \\
\hline \multicolumn{3}{|l|}{ Delta-WAI } \\
\hline Baseline to 3 months & $0.700(2.010)$ & I.273 (2.070) \\
\hline 3 to 6 months & 1.581 (1.953) & $1.917(1.491)$ \\
\hline 6 to 12 months & $1.750(2.215)$ & $1.217(2.507)$ \\
\hline \multicolumn{3}{|l|}{ Delta-MADRS-S } \\
\hline Baseline to 3 months & $6.067(8.151)$ & $10.174(7.344)$ \\
\hline $3-6$ months & $8.633(6.765)$ & 9.913 (7.530) \\
\hline $6-12$ months & $8.219(8.993)$ & $10.542(6.852)$ \\
\hline \multicolumn{3}{|l|}{ Delta-EQ-5D } \\
\hline Baseline to 3 months & $0.045(0.187)$ & $0.212(0.166)$ \\
\hline $3-6$ months & $0.124(0.155)$ & $0.253(0.129)$ \\
\hline $6-12$ months & $0.139(0.200)$ & $0.202(0.128)$ \\
\hline
\end{tabular}

Notes: Mean changes of WAI and MADRS-S as well as EQ-5D from baseline to 3, 6, and 12 months, respectively, from ICBT and TAU groups. Results adjusted for age, gender, marital status, alcohol drinking habits, and for mean changes results are also adjusted for their baseline value.

Abbreviations: EQ-5D, EuroQoL-5D; ICBT, internet-based cognitive behavior therapy; MADRS-S, Montgomery Asberg Depression Rating Scale - self-rating version; TAU, treatment-as-usual; WAI, Work Ability Index.

and $0 \%$ in the TAU group with $\alpha=0.05$ and power estimate of 0.80 . The effect size was chosen on the study group's empirical expectations as well on findings reported in a similar study. ${ }^{25}$ We were able to include 77 participants in all.

SPSS version 23 was used for statistical analyses.

\section{Ethical approval and participants consent}

The Ethics Committee of the University of Gothenburg approved the study. The trial was registered in the Swedish registry, researchweb.org, ID number 30511. All subjects gave informed consent to participate, in accordance with the provisions of the Declaration of Helsinki.

\section{Results}

The study included 77 patients, of whom 46 were randomized to ICBT and 31 to TAU. Demographic data concerning
Table 2 Linear regression analysis between work ability and MADRS-S, EQ-5D, and sick leave, respectively; all patients presented with baseline values and at 3,6, and 12 months

\begin{tabular}{llll}
\hline Variables & WAI & & \\
\cline { 2 - 4 } & B & CI & -value \\
\hline MADRS-S & & & \\
Baseline & -0.13 & -0.21 to -0.04 & 0.005 \\
3 months & -0.18 & -0.24 to -0.12 & $<0.00$ I \\
6 months & -0.16 & -0.22 to -0.09 & $<0.00$ I \\
I2 months & -0.17 & -0.23 to -0.1 I & $<0.00$ I \\
EQ-5D & & & \\
Baseline & 3.22 & 0.57 to 5.88 & 0.018 \\
3 months & 7.26 & 4.86 to 9.65 & $<0.00$ I \\
6 months & 3.59 & 0.62 to 6.56 & 0.019 \\
I2 months & 5.34 & 1.92 to 8.76 & 0.003 \\
Sick leave & & & \\
Baseline to 3 months & -0.02 & -0.05 to 0.01 & 0.18 \\
3 to 6 months & -0.02 & -0.04 to 0.01 & 0.16 \\
6 to I2 months & -0.01 & -0.04 to 0.04 & 0.94
\end{tabular}

Note: Results adjusted for age, gender, marital status, alcohol drinking habits, and group (ICBT/TAU).

Abbreviations: B, beta, unstandardized coefficient; $\mathrm{Cl}$, confidence interval; EQ$5 D$, EuroQoL-5D; ICBT, internet-based cognitive behavior therapy; MADRS-S, Montgomery Asberg Depression Rating Scale - self-rating version; TAU, treatmentas-usual; WAI, Work Ability Index.

Table 3 Linear regression analysis between delta-WAI and deltaMADRS-S as well as delta-EQ-5D, from baseline to 3,6 , and 12 months, respectively; all patients presented

\begin{tabular}{llll}
\hline Variables & B & CI & -value \\
\hline $\begin{array}{l}\text { Delta-MADRS-S } \\
\text { Baseline to 3 months }\end{array}$ & 0.17 & 0.1 I to 0.23 & $<0.00$ I \\
Baseline to 6 months & 0.12 & 0.06 to 0.18 & $<0.00$ I \\
Baseline to I2 months & 0.15 & 0.09 to 0.22 & $<0.00$ I \\
Delta-EQ-5D & & & \\
Baseline to 3 months & 3.44 & 0.89 to 5.98 & 0.009 \\
Baseline to 6 months & 2.56 & -0.85 to 5.97 & 0.14 \\
Baseline to 12 months & 2.61 & -0.80 to 6.02 & 0.13 \\
\hline
\end{tabular}

Note: Results adjusted for age, gender, marital status, alcohol drinking habits, and group (ICBT/TAU).

Abbreviations: $\mathrm{B}$, beta, unstandardized coefficient; $\mathrm{Cl}$, confidence interval; EQ$5 D$, EuroQoL-5D; ICBT, internet-based cognitive behavior therapy; MADRS-S, Montgomery Asberg Depression Rating Scale - self-rating version; TAU, treatmentas-usual; WAl, Work Ability Index.

gender, age, marital status, education level, employment, and sick leave status are shown in Table 4. There were no significant differences between the groups at baseline. The mean age of participants was 35.8 years $(\mathrm{SD}=10.6)$, and $67.5 \%$ were women, with slightly more men in the ICBT group than in the TAU group.

Table 1 and Figure $2 \mathrm{~A}-\mathrm{C}$ show mean values for work ability, depressive symptoms, and quality of life for baseline values and at 3, 6, and 12 months in the ICBT and TAU groups. The mean values differed in both groups. For example, the WAI mean value was lower in the ICBT group at baseline than in the TAU group, but the differences were not significant and vanished during the follow-ups. 
Table 4 Demographic characteristics of participants at baseline $(n=77)$

\begin{tabular}{|c|c|c|c|c|}
\hline Characteristics & Total, n (\%) & ICBT, n (\%) & TAU, n (\%) & $\begin{array}{l}p \text {-value for } \\
\text { difference }\end{array}$ \\
\hline Participants & 77 & 46 & 31 & \\
\hline Age mean & & 37 & 35 & 0.55 \\
\hline Men & $25(32)$ & $17(37)$ & $8(26)$ & 0.30 \\
\hline Women & $52(68)$ & $29(63)$ & $23(74)$ & \\
\hline \multicolumn{5}{|l|}{ Marital status } \\
\hline Single & $32(42)$ & $18(4 \mid)$ & $14(45)$ & 0.71 \\
\hline Married/cohabiting & $43(56)$ & $26(59)$ & $17(55)$ & \\
\hline \multicolumn{5}{|l|}{ Country of birth } \\
\hline Sweden & $67(87)$ & $40(87)$ & $27(87)$ & 0.99 \\
\hline Outside Sweden & $10(13)$ & $6(13)$ & $4(13)$ & \\
\hline \multicolumn{5}{|l|}{ Educational level } \\
\hline Primary/secondary & $50(65)$ & $28(6 I)$ & $22(7 I)$ & 0.64 \\
\hline University & $27(35)$ & $18(39)$ & $9(29)$ & \\
\hline \multicolumn{5}{|l|}{ Occupational class } \\
\hline High- and middle-level nonmanual & $24(3 I)$ & $16(38)$ & $8(31)$ & 0.35 \\
\hline Low-level nonmanual & $17(22)$ & $8(19)$ & $9(35)$ & \\
\hline Manual/students & $27(35)$ & $18(43)$ & $9(35)$ & \\
\hline \multicolumn{5}{|l|}{ Leisure-time physical activity } \\
\hline Never & $13(17)$ & $5(11)$ & $8(28)$ & 0.06 \\
\hline Sometimes/intensive & $62(80)$ & $41(89)$ & $21(72)$ & \\
\hline \multicolumn{5}{|l|}{ Sick leave last year } \\
\hline No & $42(54)$ & $23(50)$ & $19(61)$ & 0.33 \\
\hline Yes & $35(46)$ & $23(50)$ & $12(39)$ & \\
\hline Sick leave days last year, mean & 34 & 20 & 14 & 0.10 \\
\hline \multicolumn{5}{|l|}{ Current sick leave } \\
\hline No & $53(69)$ & \# & \# & $\#$ \\
\hline Yes & $24(3 I)$ & 14 & 10 & 0.36 \\
\hline
\end{tabular}

Notes: Distribution of age, gender, social and lifestyle variables, and sick leave status in the ICBT and TAU groups in the study. \#Missing values are not shown. Abbreviations: ICBT, internet-based cognitive behavior therapy; TAU, treatment-as-usual.

The main investigation concerned whether there was an association between WAI and MADRS-S, and EQ-5D and days of sick leave, respectively. There was a significant linear relationship between higher WAI and MADRS at follow-ups where the beta is negative (ie, the function increases as the depression/MADRS-S score reduces/decreases). Concerning quality of life, measured by EQ-5D in relation to WAI, there was a significant increase during the first 3 months in both groups, ICBT and TAU, which could be seen also in the ICBT group at 6 and 12 months (the positive beta values mean that when the function increases the quality of life/EQ-5D also increases) (Table 2). Pearson's correlation is significant at the 0.01 level (two-tailed) at 3 months: ICBT/TAU 0.69/0.60, at the 0.05 level at 6 months: ICBT 0.38 (TAU 0.25, $p=0.22$ ), and at the 0.001 level at 12 months: ICBT 0.47 (TAU 0.27, $p=0.20$ ).

There was a significant linear relationship between deltaWAI and delta-MADRS (the beta here becomes positive because of delta) (Table 3).

During the entire study period, there were no significant differences between the ICBT and TAU groups concerning number of patients with sick leave or the mean total amount of days on sick leave. In the 3, 6, and 12 months' follow-up results, the groups did not differ regarding the association between use of antidepressant and WAI (data not shown).

\section{Discussion}

The aim of this RCT was to investigate the effects of an ICBT compared to TAU on improving work ability and quality of life in patients with mild-to-moderate depression. We also wanted to examine whether patients treated with ICBT returned to work more rapidly, that is had fewer days of sick leave, than patients treated with TAU.

This study was based on the posttreatment outcome using WAI and EQ-5D as the primary outcome measures.

We could not show that ICBT improved work ability more than TAU among patients with mild-to-moderate depression. One previous study have shown that workfocused cognitive behavioral therapy can improve and maintain work participation for patients with depression. ${ }^{26}$ One explanation could, therefore, be that our study lacked an intervention with direct focus on the workplace. Further, 

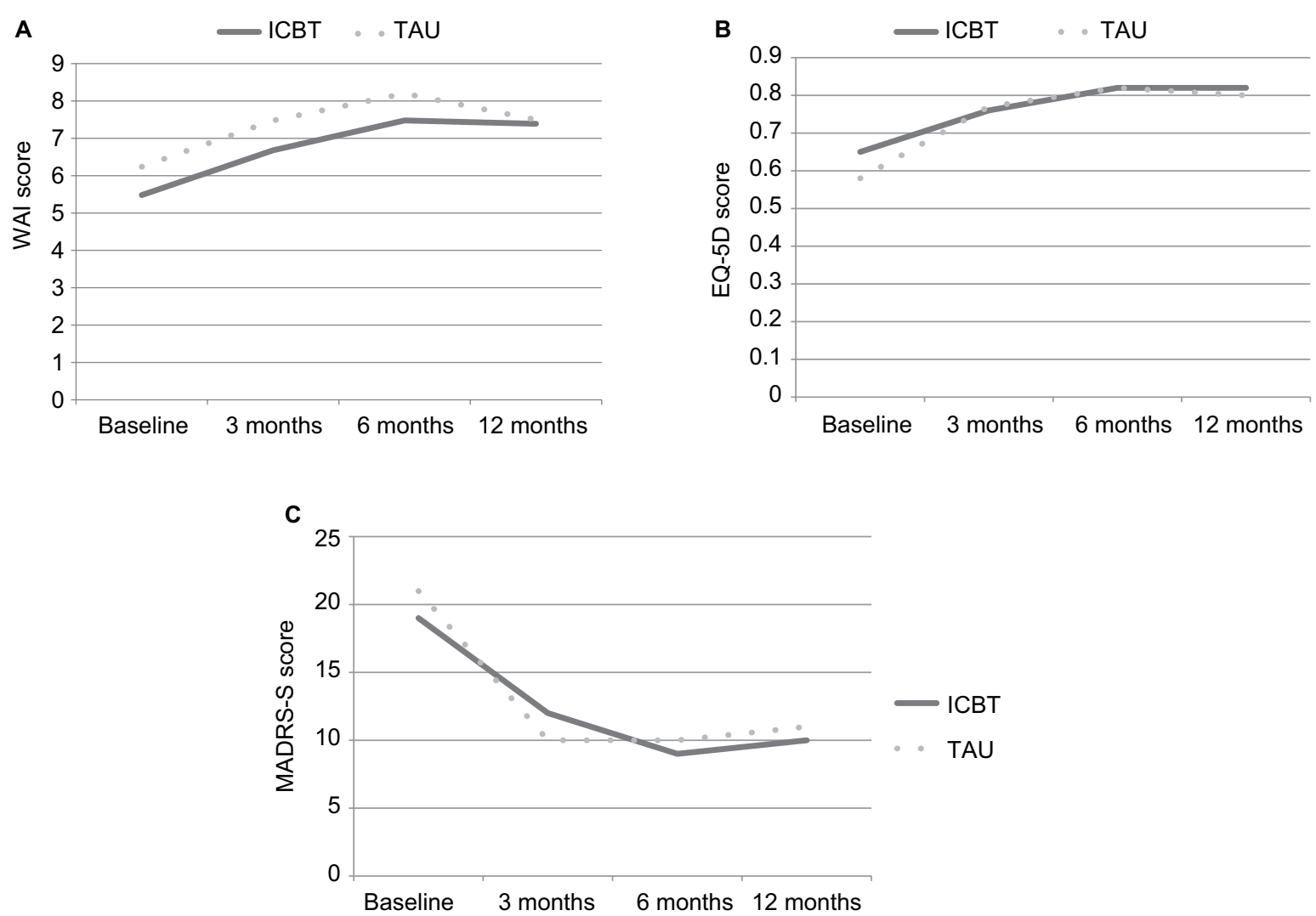

Figure 2 Mean values for (A) work ability (WAI), (B) quality of life (EQ-5D), and (C) depressive symptoms (MADRS-S) for baseline values, and at 3, 6, and I2 months in ICBT and TAU.

Abbreviations: EQ-5D, EuroQoL-5D; ICBT, internet-based cognitive behavior therapy; MADRS-S, Montgomery Asberg Depression Rating Scale - self-rating version; TAU, treatment-as-usual; WAI, Work Ability Index.

Jansson et al showed that both problem-based self-care in a group and CBT had a positive impact on the patients' ability to work. ${ }^{27}$ Imamura et al have shown a small effect of ICBT in increasing the work engagement in the general population. ${ }^{28}$ However, improvement in productivity using telephone CBT among patients with subthreshold depression could not be demonstrated. ${ }^{29,30}$

Comparing the ICBT and TAU groups, the frequency of sick-listed patients in all time intervals during the 12 months was similar, and also no significant difference was found concerning mean amount of sick-listed days during the 12 months. The patients in this study were recruited in the primary care context. The sick leave frequency among the patients during the first 3 months was around 40\%, with reduction to around $25 \%$ during the following 3 months (3-6 months after inclusion) and around 20\% during the last 6 months (6-12 months after inclusion). A majority of primary care patients treated for depression are not on sick leave during and after treatment period for depression, which is an important observation, also confirmed in the MADRS/PRISMA study (Petersson et al, unpublished data, June 2016). It is rather common that patients with depression continue their work, often with reduced productivity. ${ }^{31,32}$ Ejeby et al could not show a reduction in sick leave together with the reduction of psychological symptoms and increased well-being in patients with common mental problems in primary care. ${ }^{33}$

There was a significant association between increased work ability and reduction of depression as well as increased quality of life in all patients. This shows that all patients seemed to get better and that both ICBT and TAU were reliable treatments for patients with mild-to-moderate depression in primary care context. ICBT has previously been found to be cost-effective and can be seen as a good alternative to TAU. ${ }^{34}$ The cost-effectiveness for PRIM-NET is currently under study.

Knekt et al ${ }^{35}$ showed that long-term therapy had a better effect on work ability than short-term therapy, and that might be one of the reasons why the ICBT group (with 12 weeks of treatment) in our study did not differ significantly from the TAU group on work ability.

Finally, in future research, there is a need not only to intervene with various types of therapies to achieve better work ability in patients with mild-to-moderate depression but also to incorporate other measures, including those targeting the 
workplace. ${ }^{26,30,36,37}$ For example positive interpersonal relationships at work as well as high decision authority-relevant aspects are needed in order to prevent psychological distress. ${ }^{38}$

\section{Methodological considerations}

The strengths of this study are that it is conducted in regular primary care with a long-term follow-up perspective and that the patients have a well-defined diagnosis. Some of the limitations are the relatively small group of patients included and the lack of measures of patients' own perception of RTW.

In the the PRIM-NET trial, ${ }^{39}$ ICBT with weekly minimal therapist support was suggested to be noninferior to treatment as usual for patients with mild/moderate depression, and a treatment alternative also in the long-term perspective.

The recruitment of patients to the study was difficult. The patients who chose to participate in the study accounted for only $2.5 \%$ of all patients diagnosed with depression (all types) at participating PCCs during the study period. There is a possibility that the PCC staff did not approach all patients who were suffering from depression but instead selected patients whom they thought were internet literate and for whom they thought the ICBT would be suitable. This means that the sample of patients invited to participate in this study may be much narrower than and not representative for patients in PCC as a whole.

Other authors have also met difficulties in recruiting patients. ${ }^{30,40}$ Thus, the ODIN-2 study found a very low recruitment rate in the general population $(0.9 \%)$, when trying to recruit mild-to-moderately depressed patients, and even among a population with diagnosed depression only 3.3\% of the invited patients chose to enter the study. ${ }^{41}$ A qualitative study conducted within the PRIM-NET study concluded that it is important to include staff members when designing clinical studies. Information should be given continuously during the study and communication facilitated between different occupational groups working at the PCC. ${ }^{15}$

As our aim was to study the effectiveness in an actual PCC setting, our patients might have received other treatments for their depression during the study period. For instance, depressed patients in primary care often receive medication as soon as a depression is diagnosed, and ongoing but stable medications were allowed. Even though we have tried to track the treatment the patients received during the study, there is a risk that the two groups might not have been as equivalent as might have been possible to achieve in a more laboratory-like setting.
The EQ-5D five-dimensional questionnaire is one of the most commonly used generic questionnaires to measure HRQOL. It is highly regarded and useful in measuring patients' health but has also been criticized. ${ }^{42}$

The WAI is associated with individual characteristics, lifestyle, demands at work, and physical condition. This multifactorial nature of work ability should be taken into account in health promotion programs aimed at maintaining and promoting the participation of the labor force and improvement of the performance at work. ${ }^{43}$

An important factor that was not currently measured is the patient's own expectations of RTW after sick leave, which can be predictive of his/her actual return to work..$^{27,44}$

\section{Conclusion}

Our study indicates that a high level of work ability has an association with high HRQOL in patients with mild-tomoderate depression, whether they are treated with ICBT or TAU. ICBT has previously been found to be cost-effective and can be seen as a good alternative to TAU. In addition to the ICBT, an intervention oriented toward the work place might improve work ability and reduce the number of sick leave days among patients with depression.

\section{Acknowledgment}

This study was supported by grants from Region Vastra Gotaland and REHSAM.

\section{Disclosure}

The authors report no conflicts of interest in this work.

\section{References}

1. Alonso J, Angermeyer MC, Bernert S, et al. Disability and quality of life impact of mental disorders in Europe: results from the European Study of the Epidemiology of Mental Disorders (ESEMeD) project. Acta Psychiatr Scand Suppl. 2004;(420):38-46.

2. Bijl RV, Ravelli A. Current and residual functional disability associated with psychopathology: findings from the Netherlands Mental Health Survey and Incidence Study (NEMESIS). Psychol Med. 2000;30(3):657-668.

3. Bodlund O, Andersson SO, Mallon L. Effects of consulting psychiatrist in primary care. 1-year follow-up of diagnosing and treating anxiety and depression. Scand J Prim Health Care. 1999;17(3):153-157.

4. Koivumaa-Honkanen H, Tuovinen TK, Honkalampi K, et al. Mental health and well-being in a 6-year follow-up of patients with depression: assessments of patients and clinicians. Soc Psychiatry Psychiatr Epidemiol. 2008;43(9):688-696.

5. Adler DA, McLaughlin TJ, Rogers WH, Chang H, Lapitsky L, Lerner D. Job performance deficits due to depression. Am JPsychiatry. 2006;163(9): 1569-1576.

6. Mintz J, Mintz LI, Arruda MJ, Hwang SS. Treatments of depression and the functional capacity to work. Arch Gen Psychiatry. 1992;49(10): 761-768. 
7. Wang PS, Beck AL, Berglund P, et al. Effects of major depression on moment-in-time work performance. Am J Psychiatry. 2004;161(10): 1885-1891.

8. Martin MH, Moefelt L, Dahl Nielsen MB, Rugulies R. Barriers and facilitators for implementation of a return-to-work intervention for sickness absence beneficiaries with mental health problems: results from three Danish municipalities. Scand J Public Health. 2015;43(4):423-431.

9. Knoth RL, Bolge SC, Kim E, Tran QV. Effect of inadequate response to treatment in patients with depression. Am J Manag Care. 2010; 16(8):e188-e196.

10. Wang PS, Simon G, Kessler RC. The economic burden of depression and the cost-effectiveness of treatment. Int J Methods Psychiatr Res. 2003;12(1):22-33.

11. Welfare SNBoHa. Nationella riktlinjer för vård vid depression och ångestsyndrom 2010 - stöd för styrning och ledning. [National Guidelines for Treatment of Depression and Anxiety 2010: Support for Governance and Management]. Sweden: Socialstyrelsen; 2010.

12. Kivi M, Eriksson MC, Hange D, et al. Internet-based therapy for mild to moderate depression in Swedish primary care: short term results from the PRIM-NET randomized controlled trial. Cogn Behav Ther. 2014;43(4):289-298.

13. Montgomery SA, Asberg M. A new depression scale designed to be sensitive to change. Br J Psychiatry. 1979;134:382-389.

14. Sheehan DV, Lecrubier Y, Sheehan KH, et al. The Mini-International Neuropsychiatric Interview (M.I.N.I.): the development and validation of a structured diagnostic psychiatric interview for DSM-IV and ICD-10. J Clin Psychiatry. 1998;59 (Suppl 20):22-33; quiz 34-57.

15. Hange D, Bjorkelund C, Svenningsson I, Kivi M, Eriksson MC, Petersson EL. Experiences of staff members participating in primary care research activities: a qualitative study. Int J Gen Med. 2015;8:143-148.

16. Dimidjian S, Barrera M Jr., Martell C, Munoz RF, Lewinsohn PM. The origins and current status of behavioral activation treatments for depression. Annu Rev Clin Psychol. 2011;7:1-38.

17. Ilmarinen J. The Work Ability Index (WAI). Occup Med Oxf. 2007;57(2):160.

18. de Croon EM, Sluiter JK, Nijssen TF, et al. Work ability of Dutch employees with rheumatoid arthritis. Scand J Rheumatol. 2005;34(4): 277-283.

19. Ahlstrom L, Grimby-Ekman A, Hagberg M, Dellve L. The work ability index and single-item question: associations with sick leave, symptoms, and health--a prospective study of women on long-term sick leave. Scand J Work Environ Health. 2010;36(5):404-412.

20. Fantino B, Moore N. The self-reported Montgomery-Asberg Depression Rating Scale is a useful evaluative tool in Major Depressive Disorder. BMC Psychiatry. 2009;9:26.

21. Wikberg C, Nejati S, Larsson M, et al. Comparison Between the Montgomery-Asberg Depression Rating Scale-Self and the Beck Depression Inventory II in Primary Care. Prim Care Companion CNS Disord. 2015;17(3).

22. EuroQol G. EuroQol - a new facility for the measurement of healthrelated quality of life. Health Policy. 1990;16(3):199-208.

23. Dolan P. Modeling valuations for EuroQol health states. Med Care. 1997;35(11):1095-1108.

24. Dolan P. Modelling valuations for health states: the effect of duration. Health Policy. 1996;38(3):189-203.

25. Proudfoot J, Ryden C, Everitt B, et al. Clinical efficacy of computerised cognitive-behavioural therapy for anxiety and depression in primary care: randomised controlled trial. Br J Psychiatry. 2004;185:46-54.

26. Reme SE, Grasdal AL, Lovvik C, Lie SA, Overland S. Work-focused cognitive-behavioural therapy and individual job support to increase work participation in common mental disorders: a randomised controlled multicentre trial. Occup Environ Med. 2015;72(10): $745-752$.
27. Jansson I, Perseius KI, Gunnarsson AB, Bjorklund A. Work and everyday activities: experiences from two interventions addressing people with common mental disorders. Scand J Occup Ther. 2014;21(4):295-304.

28. Imamura K, Kawakami N, Furukawa TA, et al. Effects of an internetbased cognitive behavioral therapy intervention on improving work engagement and other work-related outcomes: an analysis of secondary outcomes of a randomized controlled trial. J Occup Environ Med. 2015;57(5):578-584.

29. Furukawa TA, Horikoshi M, Kawakami N, et al. Telephone cognitivebehavioral therapy for subthreshold depression and presenteeism in workplace: a randomized controlled trial. PLoS One. 2012;7(4):e35330.

30. Bee PE, Bower P, Gilbody S, Lovell K. Improving health and productivity of depressed workers: a pilot randomized controlled trial of telephone cognitive behavioral therapy delivery in workplace settings. Gen Hosp Psychiatry. 2010;32(3):337-340.

31. Aronsson G, Gustafsson K, Dallner M. Sick but yet at work. An empirical study of sickness presenteeism. J Epidemiol Community Health. 2000;54(7):502-509.

32. Evans-Lacko S, Knapp M. Global patterns of workplace productivity for people with depression: absenteeism and presenteeism costs across eight diverse countries. Soc Psychiatry Psychiatr Epidemiol. 2016;51(11):1525-1537.

33. Ejeby K, Savitskij R, Ost LG, et al. Symptom reduction due to psychosocial interventions is not accompanied by a reduction in sick leave: results from a randomized controlled trial in primary care. Scand J Prim Health Care. 2014;32(2):67-72.

34. Titov N, Dear BF, Ali S, et al. Clinical and cost-effectiveness of therapistguided internet-delivered cognitive behavior therapy for older adults with symptoms of depression: a randomized controlled trial. Behav Ther. 2015;46(2):193-205.

35. Knekt P, Lindfors O, Sares-Jaske L, Virtala E, Harkanen T. Randomized trial on the effectiveness of long- and short-term psychotherapy on psychiatric symptoms and working ability during a 5-year follow-up. Nord J Psychiatry. 2013;67(1):59-68.

36. van Oostrom SH, Driessen MT, de Vet HC, et al. Workplace interventions for preventing work disability. Cochrane Database Syst Rev. 2009;(2):CD006955.

37. Joyce S, Modini M, Christensen H, et al. Workplace interventions for common mental disorders: a systematic meta-review. Psychol Med. 2016;46(4):683-697.

38. Bultmann U, Kant IJ, Van den Brandt PA, Kasl SV. Psychosocial work characteristics as risk factors for the onset of fatigue and psychological distress: prospective results from the Maastricht Cohort Study. Psychol Med. 2002;32(2):333-345.

39. Eriksson MCM, Kivi M, Hange D, et al. Long-term effects of internet cognitive behavioural theory for depression in primary care - the Primnet controlled trial. Scand J Prim Health Care. In press 2017.

40. Mason V, Shaw A, Wiles N, et al. GPs' experiences of primary care mental health research: a qualitative study of the barriers to recruitment. Fam Pract. 2007;24(5):518-525.

41. Clarke G, Eubanks D, Reid E, et al. Overcoming Depression on the Internet (ODIN) (2): a randomized trial of a self-help depression skills program with reminders. J Med Internet Res. 2005;7(2):e16.

42. Ranstam J, Robertsson O, A WD, Lofvendahl S, Lidgren L. EQ-5D-a difficult-to-interpret tool for clinical improvement work. Lakartidningen. 2011;108(36):1707-1708.

43. van den Berg TI, Elders LA, de Zwart BC, Burdorf A. The effects of work-related and individual factors on the Work Ability Index: a systematic review. Occup Environ Med. 2009;66(4):211-220.

44. Nieuwenhuijsen K, Noordik E, van Dijk FJ, van der Klink JJ. Return to work perceptions and actual return to work in workers with common mental disorders. J Occup Rehabil. 2013;23(2):290-299. 
The International Journal of General Medicine is an international, peer-reviewed open-access journal that focuses on general and internal medicine, pathogenesis, epidemiology, diagnosis, monitoring and treatment protocols. The journal is characterized by the rapid reporting of reviews, original research and clinical studies across all disease areas.
The manuscript management system is completely online and includes a very quick and fair peer-review system, which is all easy to use. Visit http://www.dovepress.com/testimonials.php to read real quotes from published authors. 